\title{
El lugar del arte. Reflexiones sobre conceptos para obras arquitectónicas destinadas al arte contemporáneo
}

\section{The Place of Art. Reflections on Concepts for Architectural Works Aimed at Contemporary Art}

Artículo recibido el 24 de junio de 2019; devuelto para revisión el 29 de agosto de 2019; aceptado el 2 de septiembre de 2019; http://dx.doi.org/IO.2220I/iie.18703062e.2020.116.2713

Laura Gallardo Frías Facultad de Arquitectura y Urbanismo, Departamento de Arquitectura, Universidad de Chile. lauragallardofrias@uchilefau.cl; http://orcid. org/oooo-0003-4814-3425

Líneas de investigación Teoría y práctica de proyectos arquitectónicos.

Publicación más relevante "Totalidad en arquitectura. Reflexiones sobre la Estética y la coexistencia de las cosas con el lugar que producen en nosotros una experiencia de totalidad”, Pensamiento 73, núm. 277 (2017). https://doi.org/ıO.I4422/ pen.v73.i277.y2017.006

Resumen El objetivo del artículo es reflexionar sobre el lugar del arte contemporáneo. Se propone revisar diferentes definiciones de museos y centros de arte, así como múltiples tipologías arquitectónicas vinculadas. Una vez abierto el horizonte de significaciones, se pasa a distintas reflexiones sobre las relaciones entre los conceptos de lugar y arte contemporáneo. Más adelante, se despliega una estrategia metodológica multidisciplinaria y multimétodo que permite el estudio de cinco casos de obras arquitectónicas emblemáticas destinadas al arte contemporáneo en Santiago de Chile, donde se muestra el resultado de diversos factores en función de cuatro dimensiones: histórica, urbana, arquitectónica y sociocultural. En la discusión se analizan los principales factores a considerar tanto en el análisis como en la proyectación de obras arquitectónicas destinadas al arte contemporáneo. Se concluye con la síntesis de conceptos que llevan a una definición del lugar del arte contemporáneo.

Palabras clave Museo; centro de arte; lugar; arte contemporáneo; arquitectura.

Abstract The aim of the article is to reflect on the place of contemporary art. It reviews different definitions of museums and art centers, as well as multiple linked architectural typologies. Once the horizon of meanings opened the relationships between the concepts of place and contem- 
porary art are approached following a multidisciplinary and multimethodological strategy is deployed in five case studies of emblematic architecture destined for contemporary art in Santiago de Chile, where the out come of multiple factors is presented in four dimensions: historical, urban, architectural and sociocultural. In the discussion, the main factors to be considered in the analysis and in the design of architectural works aimed at contemporary art are examined. It concludes with the synthesis of concepts that scope to a definition of the place of contemporary art.

Keywords Museum; art center; place; contemporary art; architecture. 
DOI: https://doi.org/10.22201/iie.18703062e.2020.116.2713

\author{
LAURA GALLARDO FRÍAS \\ FACULTAD DE ARQUITECTURA Y URBANISMO, UNIVERSIDAD DE CHILE
}

\title{
El lugar del arte \\ Reflexiones sobre conceptos para obras arquitectónicas \\ destinadas al arte contemporáneo
}

Significaciones de museos y centros de arte

$\mathrm{E}$

n sus orígenes, el museo nace en el seno de la ciudad, con grandes

edificios monumentales, una suerte de templos de la cultura que determinaban un emplazamiento destacado que conectaban áreas emblemáticas, políticas y sociales. ${ }^{\mathrm{I}}$ Posteriormente, los primeros museos de arte moderno jugaron un papel simbólico y urbano de "nuevas catedrales de la modernidad urbana”, al desplazar la localización central hacia sectores de crecimiento de las ciudades, convirtiéndose en "vehículos de expansión urbana". ${ }^{2}$ Las actuaciones emprendidas por Jean Nouvel para la ampliación del Reina Sofía, consistente en tres cuerpos que generan una plaza pública interior, y el proyecto de Moneo que propone para el Prado la idea extensible al ambiente circundante, generando un paseo arquitectónico externo, son una síntesis de las propuestas de la nueva museología que cuestiona al museo como monumento cerrado y expande el campo de musealización a la propia ciudad. ${ }^{3}$ Así, del museo como objeto, entendido éste en términos lecorbusianos como "máquina expo-

I. María Ángeles Layuno R., "Museos de arte contemporáneo y ciudad. Los límites del objeto arquitectónico", en Jesús Pedro Lorente y David Almazán, eds., Museología crítica y arte contemporáneo (Zaragoza: Prensas Universitarias, 2003).

2. "Vehicles of Urban Expansion", en Jesús Pedro Lorente, Cathedrals of Urban Modernity. The First Museums of Contemporary Art, I800-1930 (Aldershot: Ashgate International, I998), I5-22.

3. Franco Minissi y Sandro Ranellucci, Museografía (Roma: Bonsignori, 1992). 
sitiva” - que si bien apuntaba hacia una transformación utópica, en la práctica experimentaba una desvinculación fuerte con su entorno, ${ }^{4}$ como sucede con el мома de Nueva York (1939)—, se pasa a la propuesta, desde mediados del siglo Xx, defendida por numerosos autores, sobre la importancia de la significación de estos centros y su necesario vínculo entre arquitectura y urbanismo, como defienden Norberg-Schulz, ${ }^{5}$ al poner de manifiesto la importancia del genius loci, de la conexión interior-exterior y la lectura de la imagen de la ciudad de Lynch. ${ }^{6}$ El Centro Georges Pompidou de París (1977), obra de los arquitectos Renzo Piano y Richard Rogers, se convierte en un referente que finaliza con la concepción de los Museos del Movimiento Moderno y da partida a la posmodernidad, con las características de la continuidad entre interior-exterior y la prolongación del espacio museístico hacia una plaza abierta a numerosas actividades, convirtiéndose este Centro en motor de regeneración cultural, anulando las fronteras entre arte y vida cotidiana. ${ }^{7}$ En la actualidad, a partir de numerosos ejemplos, no solamente teóricos, sino también construidos en muchas ciudades, los centros de arte pueden considerarse como "piezas motoras de los planes y proyectos urbanísticos de rehabilitación sectorial e integral de áreas de la ciudad histórica, debido a los poderes que se les adjudican, no sólo reestructurantes del tejido urbano, sino también socioeconómicos y simbólicos". ${ }^{8}$ Hasta llegar, incluso, a ideas del museo como un medio neutro que puede ser utilizado por cualquiera para cualquier cosa. ${ }^{9}$

Los museos y centros de arte se han definido de múltiples formas, y equiparado a distintas tipologías arquitectónicas, adquiriendo así una variada y amplia gama de significaciones. Museo deriva de la palabra musa, "lugar dedicado a las musas", "biblioteca", ${ }^{\text {,o }}$ desde su concepción inicial de "mouseion, o templo de las musas (término que originariamente significaba bosquecillo sagrado)", II

4. Fredric Jameson, Teoría de la postmodernidad (Madrid: Trotta, 200I).

5. Christian Norberg-Schulz, Genius loci (Lieja: Pierre Mardaga, 198I).

6. Kevin Lynch, La imagen de la ciudad (Barcelona: Gustavo Gili Reprints, 2006).

7. Santos Zunzunegui, Metamorfosis de la mirada: el museo como espacio del sentido (Sevilla: Alfar, I990).

8. Layuno, "Museos de arte contemporáneo y ciudad", Io9.

9. Stephen E. Weil, A Cabinet of Curiosities: Inquiries into Museums and their Prospects (Washington: Smithsonian Institution Press, 1995).

IO. Joan Corominas, Breve diccionario etimológico de la lengua castellana (Madrid: Gredos, 20I2).

II. Georges H. Rivière, La museología: curso de museología: textos y testimonios (Madrid: Ediciones Akal, 2009), 68. 
pasando por las definiciones de: tesoro de los dioses y los hombres, conservatorio, lugar de participación, lugar de investigación, lugar de colección, gabinetes de curiosidades, cámaras de maravillas, ${ }^{12}$ laboratorio, ${ }^{13}$ salón,,${ }^{14}$ escuela. ${ }^{15}$ Se han nombrado también como: cementerios, dormitorios públicos, en el Manifiesto del Futurismo de Marinetti, ${ }^{16}$ hasta mausoleos, santuarios, como recoge Francisca Hernández en la "Evolución del concepto de museo", ${ }^{17} \mathrm{o}$ instrumentos que mejoran la vida de los ciudadanos, refugios placenteros, cajas de tesoros, catalizadores de nuevas ideas, moderadores, facilitadores, y tantísimas acepciones que recopila Isabel M. García Fernández. ${ }^{18}$ Se les ha equiparado a los foros, ${ }^{19}$ a templos del placer, ${ }^{20}$ objetos eróticos, ${ }^{2 \mathrm{I}}$ a casas de tesoros donde la verdad y la belleza se descubren, a lugares donde se dan ideas estimulantes y donde se da el aprendizaje activo ${ }^{22}$ hacia la búsqueda de un sueño, una excitación..$^{23} \mathrm{E}$ incluso se les ha llamado malls y supermercados culturales. ${ }^{24}$ François Mairesse en su libro Vers une redéfinition du musée? ${ }^{25}$ propor-

I2. Rivière, La museología: curso de museología.

I3. Antonio Collados Alcaide, "Laboratorios artísticos colaborativos. Espacios transfronterizos de producción cultural”, Arte, Individuo y Sociedad 27, núm. I (2015): 45-64.

I4. Paul Valéry, Piezas sobre arte (Madrid: La Balsa de la Medusa, 2005).

I5. Roser Calaf Masachs y Sué Gutiérrez Berciano, "El Museo Thyssen-Bornemisza: evaluando sus programas educativos para enseñar arte", Arte, Individuo y Sociedad 29, núm. I (2017): 39-56.

I6. Filippo Tomasso Marinetti, "Le Futurisme", Le Figaro, 20 de febrero de 1909, publicado en la revista Prometeo II, núm. VI (1909): 90-96, trad. Ramón Gómez de la Serna.

17. Francisca Hernández, "Evolución del concepto de museo", Revista General de Información y Documentación 2, núm. I (1992): 85-87.

I8. Isabel M. García Fernández, "El papel de los museos en la sociedad actual: discurso institucional o museo participativo", Complutum 26, núm. 2 (2015): 39-47.

I9. Duncan F. Cameron, "The Museum a Temple or the Forum”, Curator, the Museum Journal I4, núm. 2 (I97I): II-24.

20. Fiammetta Rocco, "Museums. Temples of delight", https://www.economist.com/specialreport/20I8/o8/I4/temples-of-delight (consultado el 2I de diciembre, 20I8).

2I. Anna María Guasch, "Los museos y lo museal: el paso de la modernidad a la era de lo global”, Calle I4, Revista de Investigación en el Campo del Arte 2, núm. 2 (2008): I6.

22. Brian Kisida, Jay P. Greene y Daniel H. Bowen, "Arts makes you smart", en https:// www.nytimes.com/20I3/II/24/opinion/sunday/art-makes-you-smart.html, consultado el 30 de junio, 2019.

23. Victoria Newhouse, Towards a New Museum (Nueva York: Monacelli Press, 1998), 190.

24. Pablo Álvarez Domínguez y Juan Rubén Benjumea, "Aproximación al Museo Contemporáneo. Entre el templo y el supermercado cultural", Arte y Política de Identidad 5 (2011): 27-42.

25. François Mairesse y André Desvallées, Vers une redéfinition du musée? (París: L'Harmattan, 2007). 
ciona un dato interesante sobre las múltiples y variadas denominaciones de los museos a partir de una guía de museos de Francia que realizó un inventario de más de diez mil establecimientos presentando muy diversas denominaciones como: talleres, albergues-museos, herbolarios, insectarios, museos-hoteles, casas de campo, osmotecas, entre otras. ${ }^{26}$

En la evolución de la definición de museo, en particular de 1946 a 2007, se puede apreciar, además de ciertas etapas de la historia particular del museo, también la importante relación con la sociedad. ${ }^{27}$ En la definición actual, conforme a los estatutos del Consejo Internacional de Museos (ICOM), adoptados por la $22^{\text {a }}$ Asamblea General en Viena el 24 de agosto de 2007, "un museo es una institución permanente, sin fines de lucro, al servicio de la sociedad y abierta al público, que adquiere, conserva, estudia, expone y difunde el patrimonio material e inmaterial de la humanidad y su ambiente con fines de estudio, educación y recreo". ${ }^{28}$

Los museos, centros de arte y numerosas obras arquitectónicas destinadas al arte contemporáneo, entre otras funciones, como centros culturales, centros cívicos, etc., siguen abriendo distintos cuestionamientos, revisiones y críticas, que conducen a pensar: ¿por qué seguimos visitando estas obras arquitectónicas destinadas a la exhibición de arte contemporáneo? Hay muchas respuestas, ligadas a los conceptos de lugar y de arte contemporáneo; algunas de las hipótesis posibles se podrían esbozar en la idea de que los museos nos invitan a alejarnos de nosotros, a vincularnos con otros mundos, otros objetos, otros lenguajes, otras atmósferas, son auténticos "espacios otros", heterotopías como los definió Michel Foucault:

especies de contra-emplazamientos, especies de utopías efectivamente realizadas en las cuales los emplazamientos reales, todos los otros emplazamientos reales que se pueden encontrar en el interior de la cultura están a la vez representados, cuestionados

26. Alain Morley y Guy Vavasseur, Guide Dexia des 10,000 musées et collections en France, DomTom, Andorre et Monaco (París: Le Cherche Midi, 200I).

27. Julie Botte, Andrey Doyen y Lina Uzlyte, “'Ceci n’est pas un musée’: panorama géographique et historique des définitions du musée”, en François Mairesse, Définir le musée du XXIe siècle. Matériaux pour une discussion (París: ICOFOM, 2017), I7-47.

28. Consejo Internacional de Museos. Estatutos, 2007, "Artículo 3 - Definiciones, Apartado I", consultado el 2 de noviembre de 2018 , en https://icom.museum/es/actividades/normas-ydirectrices/definicion-del-museo/ 
e invertidos, especies de lugares que están fuera de todos los lugares, aunque sean, sin embargo, efectivamente localizables. ${ }^{29}$

Se podría afirmar que en la visita a los museos y centros de arte se materializan las numerosas definiciones anteriores, y pareciera que se entra en una suerte de "paralización del tiempo" o en el "lugar de todos los tiempos", ${ }^{30}$

Existe a la vez una dicotomía por ser un "aparato estético", ${ }^{31}$ que avala por una parte lo que contiene y muestra en su interior, pues se puede percibir una "protección", una cierta calma, sosiego, tranquilidad, pero, por otra parte, invitan a descubrir nuevas experiencias, sensaciones, percepciones y puntos de vista. Las obras arquitectónicas destinadas al arte contemporáneo permiten una formación continua, seguir aprendiendo, descubriendo, estimulan la creatividad y agudizan la curiosidad, y sobre todo invitan a nuevas reflexiones desde un ámbito pluridisciplinar. Así, se podría definir a los museos y centros de arte contemporáneo como una "herramienta de preguntas más que de respuestas". ${ }^{32}$

Pero, tras la enorme evolución de los museos y centros de arte, desde su ensimismamiento a su radical apertura, se abren distintas preguntas: ¿el arte contemporáneo necesita de un lugar? ¿Son compatibles los conceptos de lugar y arte contemporáneo, qué tipo de vinculaciones existen entre ambas acepciones? ¿es posible hablar del lugar del arte contemporáneo en nuestros días?

\section{Refexiones sobre los conceptos de lugar y arte contemporáneo}

Se habla de lugar y no de espacio, pues el foco de este escrito es la reflexión sobre el carácter concreto, empírico, existencial, articulado y definido, ${ }^{33} \mathrm{del}$ lugar en el arte contemporáneo. ${ }^{34} \mathrm{Y}$ se hace referencia al arte contemporáneo

29. Extracto de la conferencia "De los espacios otros", "Des espaces autres", dictada en el Cercle des Études Architecturals, I4 de marzo de 1967; Michel Foucault, "Espacios otros: utopías y heterotopías", Carrer de la Ciutat, núm. I (1978): 3.

30. Foucault, "Espacios otros", 5 .

3I. Jean-Louis Déotte, ¿Qué es un aparato estético? (Santiago de Chile: Ediciones Metales Pesados, 2012).

32. Adeline Rispal, "L’Architecture et la muséographie comme médiation sensible", Muséologies 3, núm. 2 (2009): 90-IOI.

33. Josep M. Montaner, La modernidad superada: ensayos sobre arquitectura contemporánea (Barcelona: Gustavo Gili, 20II).

34. Enrique Paniagua-Arís y Juan Roldán-Ruiz, "Traer a la presencia y dialogar con el lugar”, Arquiteturarevista IO, núm. 2 (2014): I24-I33. 
para poder acotar el arte de nuestros días, que se sucede tras el arte moderno, según afirma Badiou, ${ }^{35}$ o como indica Félix de Azúa en el Diccionario de las artes, ${ }^{36}$ el que coincide en el tiempo de su realización.

En un primer movimiento, la respuesta inmediata podría considerar que, en nuestros días, no es posible hablar de lugar del arte contemporáneo, pues a primera vista lugar y arte contemporáneo son conceptos muy distintos; sin embargo, se pueden revisar estas nociones con algo más de detalle para observar y abrir la reflexión hacia los distintos tipos de relaciones posibles.

Para la revisión de los conceptos de lugar y arte contemporáneo se parte de la hipótesis de que el arte contemporáneo abre una reflexión, una discusión, que cuestiona también al propio lugar que lo contiene. Para ello se propone un contraste entre los principales conceptos que definen al lugar, con los conceptos que definen al arte contemporáneo. Los puntos de tensión propuestos son: la historia, los límites, la identidad y el propio ser humano.

Se comienza por el punto más complejo, que es la característica de la historia. Como primera consideración, se tendría que tener en cuenta el

\begin{abstract}
"desplazamiento" propuesto por Anna María Guasch, ${ }^{37}$ desplazamiento de lo que sería una "historia de la creación" — los artistas y sus obras—, a una "historia de la recepción", donde el protagonista no es la "obra de arte", sino el "sistema del arte", que contactaría el "mundo del arte" —o mejor el "sistema del arte"— con cuestiones o factores "externos": económicos, sociales y culturales.
\end{abstract}

En lo que se refiere al arte contemporáneo se puede considerar, como indica Danto, que: "los artistas se libraron de la carga de la historia y fueron libres para hacer arte en cualquier sentido que desearan, con cualquier propósito que desearan, o sin ninguno. Ésta es la marca del arte contemporáneo y, en contraste con el modernismo, no hay nada parecido a un estilo contemporáneo". ${ }^{38}$ Este contraste es fuerte, pues como se puede revisar a partir de la definición de

35. Alain Badiou, "Las condiciones del arte contemporáneo", en http://www.kaleidoscopio. com.ar/fs_files/user_img/critica_textos/Badiou_Las\%2ocondiciones\%2odel\%20arte\%20 contempor\% $\mathrm{C}_{3} \% 83 \% \mathrm{C}_{2} \%$ Aineo.pdf (consultado el 2I de diciembre de 20I8).

36. Félix de Azúa, Diccionario de las artes (Barcelona: Anagrama, 2002).

37. Anna María Guasch, "Los museos y lo museal: el paso de la modernidad a la era de lo global", I2.

38. Arthur C. Danto, Después del fin del arte: el arte contemporáneo y la línea de la historia (Barcelona: Paidós, 1999), 37. 
Marc Augé, la historia es clave para la concepción del lugar. Según Augé, las características de un lugar, que lo permiten diferenciar de un no lugar, son la identidad, la relación con el contexto y la historia. ${ }^{39}$ Sin embargo, se podría argumentar que, si bien las obras contemporáneas van más allá de toda historia, se realizan en nuestros días, en un momento o fecha concreta. También se podría revisar en este punto además de la relación con la historia, la relación con el contexto, donde la obra de arte contemporáneo se resiste a una definición de este tipo, pero esta no relación también sería un tipo de relación.

Esta dicotomía se podría equiparar a la relación de los lugares con los nolugares, pues al igual que la racionalidad se sirve de la irracionalidad para constituirse como tal, también los lugares se sirven de los no-lugares para su constitución. ${ }^{40}$ Se abre aquí una tensión interesante. Hay que tener presente que el concepto de lugar nunca se da en términos absolutos, asemejándose el vínculo existente entre el lugar y el no-lugar a una cinta de Moebius donde, en una sola cara ambos conceptos se suceden y pueden llegar a transformarse en el otro. ${ }^{4 \mathrm{I}}$ Lo que recuerda la consideración a tener en cuenta sobre los conceptos ya que:

los conceptos están constantemente sometidos a cambios. Al crear un concepto, no se fija eternamente una verdad universal, sino que se suministra un instrumento de comprensión de la realidad que está sometido a la atmósfera de sentido de la época y que puede variar sensiblemente a lo largo de la historia. El concepto es un producto mutante de la filosofía. [...] cada concepto está relacionado con otros, de forma infinita. ${ }^{42}$

Tras recordar y tener presente la característica de constante transformación intrínseca en la esencia de los conceptos, se pasa a otro punto clave de vinculación en las acepciones de lugar y arte contemporáneo: la característica de límite. Numerosos autores han desafiado los propios límites físicos de los museos desde el "museo sin muros" de Malraux donde cada uno puede imaginar su

39. Marc Augé, Los no lugares, espacios del anonimato: una antropología de la sobremodernidad (Barcelona: Gedisa, 1998).

40. Walter Benjamin, Discursos interrumpidos I (Buenos Aires: Taurus, 1989).

4I. Laura Gallardo Frías, "Vínculo interior-exterior: una reflexión sobre la arquitectura del lugar y el no-lugar", Revista RI80, núm. 27 (20II): 2-5

42. Michele Botto, Del ápeiron a la alegría: la subjetividad en Deleuze (Madrid: Universidad Autónoma Metropolitana Ediciones, 2014), 23. 
propio museo. ${ }^{43}$ Una materialidad que también interroga Lyotard en el proyecto curatorial de Les Inmateriaux (1985), donde reflexiona sobre el vaivén de la materialidad y la inmaterialidad. El paso al museo en movimiento o incluso su "portabilidad" a partir de dispositivos móviles como la obra de Marcel Duchamp Boîte-en-valise (194I). Hasta los conceptos de desplazamiento, porosidad y transitividad propuestos por Nicolás Bourriaud. ${ }^{44}$ Y la disolución entre el adentro y el afuera planteada por Rancière. ${ }^{45}$

El concepto de "lugar" también se define por la característica de "límite", como afirma Norberg-Schulz, "el lugar es siempre limitado", siendo creado por el ser humano y montado para su especial finalidad. ${ }^{46}$ Así, las acciones sólo tienen significación en relación con lugares particulares y están coloreadas por el carácter del lugar. Sin embargo, en la definición de arte contemporáneo está inmersa la "característica de la no especificidad de la obra de arte, que trae consigo la bifurcación de la filosofía del arte y de la teoría del arte". 47 También se encuentra en el concepto de "arte contemporáneo", una crítica, no sólo hacia la noción misma de la obra y del arte, sino una crítica a la noción finita de la obra..$^{8} \mathrm{Y}$ mientras el lugar es "único e inexplicablemente maravilloso", 49 la noción de arte contemporáneo está sometida a dos normas, como explica Alain Badiou, ${ }^{50}$ por una parte, a la posibilidad de repetición, cualidad introducida por Walter Benjamin ${ }^{51}$ con la idea de reproductibilidad de la obra de arte, y en segundo lugar por el ataque a la figura del artista. Se podría hablar de un potente diálogo entre estos conceptos ya que, si bien el concepto de lugar está definido por sus límites, también en estos límites existe una apertura, una relación entre el interior y el exterior en permanente movimiento, pues es necesa-

43. André Malraux, El museo imaginario, Las voces del silencio. Visión del arte (Buenos Aires: Emecé, 1956).

44. Nicolás Bourriaud, Radicante, trad. M. Guillemont (Buenos Aires: Adriana Hidalgo, 2009).

45. Jacques Rancière, Sobre políticas estéticas (Barcelona: Museu d'Art Contemporani de Barcelona Servei de Publicacions de la Universitat Autònoma de Barcelona, 2005).

46. Christian Norberg-Schulz, Existencia, espacio y arquitectura (Barcelona: Blume, 1980), I9.

47. María del Carmen Oleas, "Arthur Danto: ¿Arte post-histórico o arte contemporáneo?”,

Tsantsa. Revista de Investigaciones Artísticas, núm. I (2014): 9.

48. Badiou, "Las condiciones del arte contemporáneo", 2013.

49. Álvaro Siza, "Álvaro Siza I995-1999", El Croquis, núm. 95 (1999): 44.

50. Badiou, "Las condiciones del arte contemporáneo", 2013.

5I. Walter Benjamin, "La obra de arte en la época de su reproductibilidad técnica", en Sobre la fotografía (Valencia: Pre-Textos, 2004). 
rio que los lugares nos llamen hacia su interior, pero también que nos hagan soñar con el exterior.

Esta posibilidad de apertura está vinculada con la identidad. Danto explica que en la época actual la mímesis ya no es la finalidad del arte, sino la búsqueda de su propia identidad. Es en esta búsqueda de identidad donde el arte niega las respuestas que encuentra sobre sí mismo, el "arte llega a su fin con el advenimiento de su propia filosofía". ${ }^{22}$ Así, tanto la institución del arte como el artista y la obra buscan en la reflexión y la explicación teórica haciendo desaparecer casi al objeto, como explica Oleas ${ }^{53}$ y con un foco en el sujeto y su reflexión. La característica de la identidad también es una de las que definen a la noción de lugar. Norberg-Schulz indica que identidad significa que los objetos son lo que ellos desean ser, y está íntimamente conectada con la experiencia del lugar. Este autor afirma que lugar es "algo más" que una localización abstracta, es "un concreto 'aquí" con su identidad particular" 54 y subraya el carácter o interacción recíproca con lo que lo rodea: "un lugar es un espacio con un carácter que le distingue". ${ }^{55}$ Es muy provocador este concepto para el vínculo del lugar con el arte contemporáneo, pues al hacer referencia a su propia definición, según la Real Academia Española, se encuentra que la identidad implica tanto la cualidad de lo idéntico como la que lo caracteriza, es decir, las diferencias. "La identidad es en sí un fracaso, pues requiere una exploración que lleva a volver a encontrarse, pero al volver al yo ya es otro" ${ }^{56}$ La identidad requiere de una continua exploración, una continua búsqueda que en sí encierra la esencia de la identidad del lugar y también la esencia del arte contemporáneo.

$\mathrm{El}$ ser humano es clave en esta vinculación de conceptos lugar-arte contemporáneo. En la noción de lugar se cita a Heidegger cuya pregunta por el ser es la que motiva toda su filosofía y es el primero en destacar, como indica Norberg-Schulz, que "la existencia es espacial", afirmando que no puede disociarse al ser humano del espacio. ${ }^{57}$ Se considera al ser humano como "centro del proyecto arquitectónico y principal lugar" 58 cuya naturaleza implica estar en

52. Arthur Danto, "El final del arte", El Paseante 22-23 (1995): I2-I3.

53. Oleas, "Arthur Danto: ¿Arte post-histórico o arte contemporáneo?”, I2.

54. Norberg-Schulz, Genius loci, 7.

55. Norberg-Schulz, Genius loci, 5 .

56. Emmanuel Lévinas, Humanismo del otro hombre (México: Siglo XXI, 2006), II6.

57. Norberg-Schulz, Existencia, espacio y arquitectura, I8.

58. Laura Gallardo Frías, "Lugar y Arquitectura. Reflexión de la esencia de la arquitectura a través de la noción de Lugar", Arquiteturarevista 9, núm. 2 (2013): I62. 
DOI: https://doi.org/10.22201/iie.18703062e.2020.116.2713

la tierra como mortal, lo que significa habitar. Y para llevar el habitar a la plenitud de su esencia, como describe en Construir, habitar, pensar, se debe pensar y construir desde el habitar. ${ }^{99}$ En concordancia con esta idea central del ser humano, se destaca que una ambición del arte contemporáneo es crear "arte viviente", en sentido estricto, es decir, reemplazar la inmovilidad de la obra por el movimiento de la vida, como indica Alain Badiou:

El arte contemporáneo va a tomar, entonces, otra dirección, que estará ligada a los efectos que produce: el arte no será un espectáculo, ni una detención del tiempo, más bien será lo que compromete en el tiempo mismo y produce efectos en el tiempo. Se podría incluso decir que el arte clásico es una instrucción para el sujeto, una lección para el sujeto y, en cambio, la obra contemporánea apunta hacia una acción que cuestiona y transforma al sujeto. ${ }^{60}$

En el arte contemporáneo, según explica Badiou en el texto citado anteriormente, existen dos formas características, el performance y la instalación, la primera vinculada con el tiempo y la segunda con el espacio. También el lugar se conforma en la coexistencia de tiempo y espacio, como define Leibniz y después sintetiza Hegel "tiempo en espacio". "Unión del espacio y el tiempo, en la que el espacio se concreta en un ahora, al mismo tiempo que el tiempo se concreta en un aquí", como indica Muntañola, ${ }^{61}$ aspirando a una totalidad. ${ }^{62}$

Habría que tener presente la característica del sujeto nómade o en tránsito, al igual que la propia museología crítica. ${ }^{63}$ Un sujeto "destinado al exilio fuera de sí y conminado a inventar la cultura nómade que el mundo contemporáneo le exige", ${ }^{64}$ donde no cuenta con un territorio estable. Por tanto, si bien los nuevos espacios de arte deben entender las características de constante mutación, desarrollo, cambio y diversidad, sin embargo, se hace necesario

59. Martín Heidegger, Construir, habitar, pensar (Barcelona: Serbal, 1997).

6o. Badiou, "Las condiciones del arte contemporáneo", 3.

6I. Josep Muntañola, La arquitectura como lugar (Barcelona: Gustavo Gili, 1974), 23-24.

62. Muntańola define también al lugar en su obra Topogénesis, como un constante y triple encuentro entre el medio externo, nosotros mismos y los demás, y cada lugar construido es una síntesis y un resultado de este triple encuentro. Josep Muntañola, Topogénesis: fundamentos de una nueva arquitectura (Barcelona: Ediciones UPC, 2000).

63. Francisca Hernández Hernández, Planteamientos teóricos de la museología (Gijón: Trea, 2006).

64. Bourriaud, Radicante, 87. 
que reciban en un espacio concreto: a los artistas, a los visitantes... Cualidad de recibir que remite directamente a la khôra platónica.

Así, para terminar este apartado de contrastes de conceptos es necesario ir a una de las nociones más relevantes y potentes que definen el lugar, propuesta por Platón en el Timeo: la khôra, chora o jöra, definido como aquello en lo cual algo deviene, el espacio de su devenir sentido o "nodriza del devenir". ${ }^{65}$ El filósofo expone que la naturaleza que recibe todos los cuerpos es siempre idéntica a sí misma, aclarando que no cambia en nada sus propiedades, y como ha de tomar todas las especies en sí misma, lo que recibe — de ahí la denominación de receptáculo- es necesario que se encuentre exento de toda forma. ${ }^{66}$ Derrida afirma que la khôra es más situante que situada e indica que debemos referirnos a ella sin un artículo determinado, pues khôra no es, no da nada dando lugar: hay khôra, pero la khôra no existe, puesto que recibe para darles lugar a todas las determinaciones pero ella no posee ninguna propia. ${ }^{67} \mathrm{Con}$ lo que se podría proponer que las obras arquitectónicas destinadas al arte contemporáneo necesitan de un lugar que encierre su significación más radical, que contenga la esencia de khôra platónica, que recuerda también a la definición del Aleph de Borges como "el lugar donde están, sin confundirse, todos los lugares del orbe, vistos desde todos los ángulos" ${ }^{68}$ Un receptáculo abierto a recibir, cuyos factores relevantes se revisan a continuación.

65. Platón, Timeo o de la naturaleza, trad. Gustavo Saboia, en https://www.philosophia. cl/biblioteca/platon/timeo.pdf (Santiago de Chile: Universidad ARCIs-Escuela de Filosofía, 2009), 26.

66. Platón, indica Pérez-Gómez, entiende que la verdad absoluta y la bondad, al igual que el sol, nunca se pueden contemplar directamente, siendo un objeto de conocimiento puro, sino más bien tienen que ser experimentadas como la iluminación que hace posible que las cosas de este mundo sean lo que son, como un reflejo en el espejo, en la chôra. Así, la obra de arte que permite tal iluminación pueda percibirse como chôra, como espacio de la creación y la participación humana, postulando a una coincidencia entre topos y chôra. Alberto Pérez-Gómez, "Chora: The Space of Architectural Representation”, en Alberto Pérez-Gómez y Stephen Parcell, Chora. Intervals in the Philosophy of Architecture, vol. I (Montreal: McGill-Queen's University Press, 1994), I-34.

67. Jacques Derrida, Khôra, trad. Horacio Pons (Buenos Aires: Amorrortu, 20II).

68. Jorge Luis Borges, El Aleph (Madrid: Alianza, 200I), 64. 
DOI: https://doi.org/10.22201/iie.18703062e.2020.116.2713

\section{Factores relevantes para obras arquitectónicas destinadas al arte contemporáneo a partir de cinco casos de estudio}

Durante dos años, con un equipo multidisciplinario compuesto por antropólogos, historiadores y arquitectos, ${ }^{69}$ se analizaron cinco casos de estudio de obras arquitectónicas públicas emblemáticas destinadas al arte contemporáneo en Santiago de Chile: ${ }^{70}$ el Museo de Arte Contemporáneo del Parque Forestal, Museo de Arte Contemporáneo de Quinta Normal, Centro Cultural Gabriela Mistral, Centro Cultural la Moneda y Centro Nacional de Arte Contemporáneo de Cerrillos. El objetivo fue analizar, desde la perspectiva del lugar, a partir de la dimensión histórica, urbana, arquitectónica y sociocultural, obras emblemáticas de arquitectura pública destinadas al arte contemporáneo en la vinculación con sus visitantes y su contexto.

Como metodología se despliega una estrategia multidisciplinaria y multimétodo que permite producir conocimiento para cada una y todas las dimensiones analizadas. Para la recolección de la información se construye una matriz de análisis de datos. ${ }^{71}$ En ella se identifican las dimensiones y sus factores de análisis. Esta matriz permite cruzar la dimensión histórica, urbana y arquitectónica con la sociocultural. Para recolectar la información se aplican metodologías específicas. En la dimensión histórica se recopilan y analizan documentos históricos, material bibliográfico e información secundaria. En la dimensión urbana se realiza un estudio planimétrico en tres escalas: ciudad, comuna y barrio, con superposición de capas de información. En la arquitectónica se trabaja una planimetría de base que se estructura en una secuencia desde el exterior hacia el interior. $Y$ en la dimensión sociocultural se realiza un trabajo de tipo etnográfico que incluye observación participante y entrevistas. La información recolectada se vacía en la matriz.

69. Agradecimientos a todo el equipo de investigación: María Isabel Toledo Jofré, antropóloga; Consuelo Figueroa Garavagno, historiadora; Soledad Novoa, historiadora; Luis Pérez Huenupi, arquitecto; Javier Vera Bravo, antropólogo, y Paulina Román Manzo, comunicadora social.

70. Agradezco a las directoras y los directores de los cinco casos de estudio que nos ayudaron en nuestra investigación: Francisco Brugnoli, director del Museo de Arte Contemporáneo-MAC Parque Forestal y MAC Quinta Normal; Beatriz Salinas, directora del Centro Nacional de Arte Contemporáneo Cerrillos; Felipe Mella, director del Centro Cultural Gabriela Mistral-gam; Beatriz Bustos, directora del Centro Cultural la Moneda. Y a todos sus equipos y colaboradores.

7I. Matthew B. Miles, Michael Huberman y Johnny Saldaña, Qualitative Data Analysis: a Methods Sourcebook (Los Ángeles: SAgE Publications, Inc., 20I4). 
Tras el análisis de los cinco casos de estudio mencionados, se ajustó la matriz y se sintetizaron los factores generales de análisis, en conjunto con factores específicos. Estos factores pueden considerarse tanto para el análisis como para la proyectación de obras arquitectónicas destinadas al arte contemporáneo.

En la dimensión histórica, los factores relevantes que se proponen son tres: la historia del terreno, la historia de la edificación —indicando tanto para la construcción como para las distintas remodelaciones: mandante, arquitecto, fecha, estilo arquitectónico, materiales, uso, contexto histórico, políticas culturales asociadas-, y la historia de la institución.

Para la dimensión urbana, los principales factores a considerar, en las escalas de la ciudad, la comuna y el barrio, son: clima, topografía, emplazamiento, legibilidad, relación llenos-vacíos y alturas, usos de suelo, sistema de red de equipamientos de arte, conectividad vial y de transporte, flujos de personas, áreas verdes y factores sensoriales como: vistas, colores, sonidos, olores, texturas, entre otras.

En lo que respecta a la dimensión arquitectónica los factores de análisis a tener en cuenta son: la geometría (forma de la envolvente y su relación con el entorno), accesos, fachadas programa (descripción de recintos, $\mathrm{m}^{2} \mathrm{y}$ articulación entre los distintos recintos), espacios servidores y espacios servidos, estructura, materiales (cielos, muros, suelos), colores, texturas, luz natural y luz artificial, vistas, acústica y climatización.

Y en la dimensión sociocultural los factores de análisis, al ser una dimensión central, se consideran, además de sus propios factores, el entrecruzamiento con las otras dimensiones. Así, los factores propios de esta dimensión son: usos del espacio, tipos de usos, estilos de visita, tiempo de visita, mapa de actores y estructura de relaciones, conflictos, solidaridades, relaciones entre visitantes y objetos de arte, normas de permanencia y pautas de comportamiento, tipos de trayectorias de recorrido (preestablecida, espontánea, guiada), usos de tecnología de registro, valoraciones, y recomendaciones para el lugar del arte. Con relación al entrecruzamiento con la dimensión histórica: historias del edificio y el lugar, historias de la institución según el visitante. Respecto a la dimensión urbana: variaciones del uso del espacio según la condición climática, valoración de ubicación en la ciudad, en la comuna, en el barrio y en la manzana. Legibilidad: reconocimiento del edificio como lugar de arte, circuitos entre el centro y otros espacios, uso de red de centros. Conectividad vial: vías utilizadas, conocimiento de vías de acceso, experiencia de viaje, uso de medios de transporte, medios de transporte utilizados, valoración del viaje, percepción 
temporal de viaje, prácticas de tránsito, tránsito y permanencia. Zonas verdes: usos, conflictos y valoraciones. Representaciones de: paisajes, sonidos, olores del sector. Vinculado al entrecruzamiento de la dimensión arquitectónica se destacan las valoraciones del edificio: forma, contexto, materialidad; percepción de proporciones, legibilidad de accesos y salidas de emergencia, accesibilidad universal, invitación a entrar, comprensión de señalética, relación interior-exterior, percepción y valoración de fachadas, espacios servidores y servidos (caracterización de sujetos, normas y prácticas de uso, valoraciones), valoración de la institución (misión, visión, objetivos, estructura y política organizacional, programa artístico, difusión, relación con circuito cultural), salas de exposición (prácticas de uso, conflictos por el uso, valoraciones), personal (directivo, técnico, administrativo, auxiliar, seguridad), actividades y recursos de mediación (visitas guiadas, talleres, conversatorios).

La enumeración de los factores expuestos permite comprender la gran complejidad de las obras arquitectónicas destinadas al arte contemporáneo, pues muestran los numerosos puntos a tener presentes en estos lugares para analizarlos a profundidad.

Tras este análisis de los factores relevantes, realizamos un entrecruzamiento de las dimensiones: histórica, urbana, arquitectónica y sociocultural para llegar a sintetizar cinco puntos clave en las obras arquitectónicas destinadas al arte contemporáneo. I) Conectividad, la importancia de una red de conexión con toda la ciudad y la calidad del transporte, en conjunto con un emplazamiento simbólico; 2) legibilidad, que el lugar del arte sea un hito urbano "fácilmente identificable" 72 y que también se conecte con el pasado, el presente y que se abra hacia el futuro; 3 ) accesibilidad. Es clave la "porosidad" en la edificación, que invite a entrar, que sea accesible para todas las personas y existan distintas proporciones entre los distintos tipos de accesos; 4) recorridos y permanencias. Será relevante comprender el centro o museo desde el acceso, pero también que invite a descubrirlo, para lo cual favorecen las distintas proporciones de salas, la señalética, la diferenciación entre los espacios servidores y los espacios servidos. ${ }^{73}$ También se destacan los lugares de permanencia, tanto al interior de las salas de exhibición, como en terrazas, cafeterías, plazas exte-

72. Lynch, La imagen de la ciudad, II.

73. Se hace referencia a la distinción propuesta por Louis I. Kahn entre los espacios de tránsito versus los espacios de permanencia. Louis I. Kahn, Forma y diseño (Buenos Aires: Nueva Visión, 2003). 
riores, entre otros, que permitan prolongar la visita; 5) flexibilidad. Habría que entender esta característica desde sus múltiples enfoques, como una apertura a las distintas posibilidades, tanto en su concepción como en su materialización. Que el lugar de arte sea capaz de exponer obras de distintos tamańos, tanto en el interior como en el exterior. La existencia de iluminación natural que pueda combinarse con iluminación artificial. Flexibilidad espacial, de distintas opciones de recorridos, de "movimientos" de salas. Y la conexión entre interior-exterior. A estas características habría que sumar la programación, tipo y calidad de las obras expuestas. ${ }^{74}$

\section{Hacia una definición del lugar del arte contemporáneo}

El paradigma de lo contemporáneo es el collage, tal como fue definido por Max Ernst, pero con una diferencia: Ernst dijo que el collage es "el encuentro de dos realidades distantes en un plano ajeno a ambas". La diferencia es que ya no hay un plano diferente para distinguir realidades artísticas, ni esas realidades son tan distantes entre sí. Esto se debe a que la percepción básica del espíritu contemporáneo se formó sobre el principio de un museo en donde todo arte tiene su propio lugar, donde no hay ningún criterio a priori acerca de cómo el arte deba verse, y donde no hay un relato al que los contenidos del museo se deban ajustar. [...] El museo es un campo dispuesto para una reordenación constante..$^{75}$

Las obras arquitectónicas destinadas al arte constituyen una de las tipologías donde más se ha explorado, ya que han sido, no solamente definidas, sino también construidas a partir de una gran cantidad y variedad de conceptos, lo que se puede comprobar en numerosos ejemplos. Desde el Altes Museum (1830), edificación más antigua destinada a este fin. ${ }^{76}$ Con sus características de tem-

74. Pierre Bourdieu, Alain Darbel y Dominique Schnapper, El amor al arte: los museos europeos y su público (Buenos Aires: Paidós, 2004).

75. Danto, Después del fin del arte, 28.

76. "El Altes Museum (o Schinkelbau, por el nombre de su arquitecto), es el más antiguo del conjunto berlinés de la Isla de los Museos y el edificio más antiguo construido para uso como museo. Tanto en Europa como en América, el estilo neoclásico de su fachada ha servido de modelo a numerosos museos del siglo xix. Su solemne disposición preparaba ya desde el primer momento al visitante en aquel ambiente de templo, lo que hoy día sería censurable". Rivière, La museología: curso de museología: textos y testimonios, 72. 
plo; el museo de crecimiento ilimitado de Le Corbusier (1939), con una forma rectilínea que se enrosca sobre sí mismo; el Museo para una pequeña población de Mies van der Rohe (1942), como "platónico museo de planta libre"; 77 el Museo Guggenheim de Nueva York (1959) de Frank Lloyd Wright, que invita a ser recorrido en todo su perímetro con la rampa helicoidal; el Museo de Arte de Sao Paulo, obra de Lina Bo Bardi (I968), que se levanta para dejar pasar la ciudad a su través y propone una nueva forma de exponer las obras con la idea de ver la totalidad espacial; el Kimbell Art Museum de Louis I. Kahn (1972), donde la luz se convierte en una herramienta magistral que le da vida; el Centro Georges Pompidou (1977), de Renzo Piano y Richards Rogers, que marca un hito por abrirse a la ciudad. Al igual que el Guggenheim de Bilbao de Gehry (1997), que regenera un sector industrial y este "efecto Guggenheim", ${ }^{78}$ ha sido replicado en numerosas ciudades. Así, se encuentran museos y centros de arte que se fusionan con su emplazamiento como el Landscape Formation One de Zaha Hadid (1999), el Museo Soulages, obra de RCR (2014) o el Museo de Altamira (200I) de Navarro Baldeweg; hasta elementos que marcan un hito como el Museo de Arte Nanjing Sefang (20II) de Steven Holl, o el Louvre Abu Dhabi (2017) de Jean Nouvel. Museos de múltiples características, como define Montaner que atraviesan desde formas irrepetibles, hasta llegar a la caja polifuncional, neutra y repetible. ${ }^{79}$

¿Cómo definir entonces el lugar del arte contemporáneo? Danto indica que el arte contemporáneo es demasiado pluralista en intenciones y acciones como para permitir ser encerrado en una única dimensión. Propone comprometer al arte directamente con la vida de aquellas personas que no han visto razón para utilizar el museo ni como un tresorium de belleza, ni como un santuario de formas espirituales. Por tanto, el desafío es "ofrecer un camino y ser diferentes, quizá muy diferentes de lo que han sido desde hace mucho tiempo", ${ }^{\circ}$ en una constante reordenación.

La definición de un lugar para el arte contemporáneo es una tarea muy compleja, aquí solamente me atrevo a adelantar una especie de pequeño esbozo que pueda seguir despertando y abriendo reflexiones. Se propone considerar el

77. Josep M. Montaner, Museos para el siglo XXI (Barcelona: Gustavo Gili, 2003), IO.

78. Domínguez y Benjumea, "Aproximación al Museo Contemporáneo. Entre el templo y el supermercado cultural”, 20II y Ińaki Esteban, El efecto Guggenheim del espacio basura al ornamento (Barcelona: Anagrama, 2007).

79. Montaner, Museos para el siglo XXI, 2003.

80. Danto, Después del fin del arte, 39. 
receptáculo donde se manifiesten las necesidades, expresadas por los visitantes $\mathrm{y}$ artistas, tener presente la significación del arte contemporáneo y por supuesto la definición de lugar. Así, para hacer un primer esbozo de definición del lugar del arte contemporáneo, habría que considerar una obra arquitectónica conectada a la ciudad y al barrio, con alto grado de legibilidad y accesibilidad. En éste habrán de combinarse los recorridos con las permanencias y tener la suficiente flexibilidad para acoger a las diferentes opciones de arte contemporáneo que necesitan distintas proporciones, espacios, conexiones del interior con el exterior, que permitan a su vez: el "movimiento" de la reflexión, la búsqueda continua de identidad, crítica y una conexión con el ser humano, que lo vincule directamente con la noción de lugar, en una relación con su historia y su contexto. Y, si bien existen ciertos límites, se da la noción de apertura, de continua búsqueda como el concepto de identidad que fusiona el arte contemporáneo con el lugar, la relación con el ser humano y sobre todo la capacidad de recibir, de ser una auténtica khôra, remitiéndose a la definición de recepción del lugar.

Al sintetizar estos conceptos, se podría definir el lugar del arte contemporáneo como una khôra o nodriza del devenir con el ser humano como centro que, si bien es legible y limitado, está abierto a recibir, a la posibilidad de su constante definición, reflexión y búsqueda de identidad. \$

N.B. Este artículo forma parte del proyecto de investigación FONDECYT no III7OI40, titulado: "El lugar del arte contemporáneo en Santiago de Chile. Análisis de obras emblemáticas de arquitectura pública y su vinculación con los habitantes desde la dimensión histórica, arquitectónica, urbana y sociocultural”, financiado por el Fondo Nacional de Desarrollo Científico y Tecnológico de Chile. 